\title{
Study on the Influence of Vertical Channel Conflict on the Changing Trend of Channel Cooperation Qiuping Yong ${ }^{1, a^{*}}$,Xiaoyan $\mathrm{Wu}^{2, \mathrm{~b}}$
}

\author{
1.School of management, Wuhan university of technology, Wuhan,Hubei, 430070 , China \\ 2.School of management, Wuhan university of technology, Wuhan,Hubei, 430070 , China \\ a1451175467@qq,com , b1055383683<wxy8801@qq.com
}

Keywords: Vertical channel conflict; Channel cooperation; Supplier; Retailer

\begin{abstract}
With the intensification of market competition and the tendency of product homogeneity, the problem of channel conflict is becoming more and more obvious. In general, channel conflict is divided into three types: vertical channel conflict, multi-channel conflict and horizontal channel conflict. This article mainly analyzes the vertical channel conflict, the vertical channel conflict common performance of the conflict between the supplier and the retailer, the manufacturer and the dealer conflict, this article uses the case analysis method to the Nanchang department store event as an example, focuses on the supply Conflict between business and retailer. When the supplier provides the goods to the retailer, it will encounter an unreasonable charge of the entry fee. Therefore, this article is from the supplier's point of view. This paper analyzes the causes and results of the events by reproducing the events of the Nanchang department store, and puts forward a series of methods to solve the conflict of the vertical channels.
\end{abstract}

\section{Introduction}

Vertical channel conflict is the most studied in the theory of channel conflict, because in the marketing channel, the vertical conflict is not only frequent, but also through the channel conflict mediation can better meet the needs of consumers, thereby enhancing the competitiveness of enterprises, Good vertical channel relationship is a smooth and effective operation of the channel prerequisites, and the relationship depends on the behavior of both sides (including conflict and conflict resolution).

\section{Vertical Channel Conflict Process}

\section{The Source of Conflict Phase}

Into the attitudinal souces of conflict and the structural souces of conflict. The attitude of the attitude of the conflict refers to the differences between the channel members due to the different environmental information received and processed, such as their role in the channel, the channel expectations and awareness, and so have different views[1]. The structural root of the conflict refers to the differences or opposition of the members of the channel, such as the inconsistency of the target, the self-consciousness and the behavior, and the competitive relationship formed by the scarcity of resources. The root cause of the channel conflict is the same time with the channel cooperation, but in the root stage, the conflict is potential, no surface, people often do not realize.

\section{Perceived or Emotional Conflict Stage}

Under the influence of some external forces, such as the channel members in the signing of the supply and marketing contracts to bargain, the market environment forcing the channel members to force the consideration of the signed supply and marketing contracts, a channel members to use the mandatory power of another channel members do some of the latter The conflict will become perceivable, and thus enter the second stage of the channel conflict, that is, cognitive or affective 
conflict stage. Perceived or emotional conflict refers to the conflict is felt, and caused the tension between the members of the channel, so that channel members have concerns or dissatisfaction with each other[2]. At this stage, although the conflict was felt, and caused a certain degree of emotional dissatisfaction, but still not to channel members of this dissatisfaction in the action.

\section{Phenomenon Conflict Stage}

When the channel members will be their dissatisfaction in the action, the channel conflict to rise to the phenomenon of conflict . Phenomenon Conflict refers to a channel member taking practical action to prevent another channel member from achieving his or her goals. At this stage, the relationship between the channel members is very tense, need to mediate, otherwise, the conflict will intensify, and ultimately make the partners into enemies.

\section{Conflict of Potential or Actual Consequences}

Regardless of whether the conflict is resolved or not, the channel conflict will go to the final stage, the potential or actual conflict outcomes stage of the conflict. The results of the conflict are not necessarily bad (Magrath and Hardy, 1989; Rosenbloom, 1973). In general, channel conflicts include both pathological and functional conflicts[3].

\section{"Shocking" Nanchang Department Store Event}

\section{"The Most Distinctive" Vertical Channel Conflict Nature}

June 2001, the hot Nanchang was "department store event" stirred uproar. People familiar with some of the non-staple food such as good potato chips, A Ming melon seeds, five state beef jerky and so on in the department store can not buy. Crazy more than 200 non-staple food brands will be evacuated from the department store, 25 suppliers together to resist the Nanchang department store, some suppliers also chose to terminate the cooperation with the department store, there are some because they do not want to give up this "feng shui treasure" And choose to swallow. Seems to be the cost of the supplier and the department store, but in fact the department store domineering and power.

Vertical channel conflict is the most characteristic conflict in the channel, the vertical conflict is the conflict between members of each other, because there is a conflict to cooperate. The conflict between the supplier and the retailer is a vertical conflict. Conflicts between suppliers and department stores in this case are vertical channel conflicts.

\section{Conflict "Many" Causes}

The hypocrisy under the Unequal Treaty is the origin of this event, and the conflict between the supplier and the department store is due to the commercial status of the department store and its high popularity and becoming the preferred shopping destination for consumers[4]. Kind of "domineering". The entry threshold is high and there are a variety of charges.

In general, suppliers to pay "admission fee", "display fee", "end of the cost", "heap charges." Not only that, met the Spring Festival, New Year's Day, the Dragon Boat Festival, Mid-Autumn Festival and department store shops, but also buckle suppliers $10 \%$ to $15 \%$ of the purchase price, the United States called "deduction point."

In such a high pressure, some suppliers have to withdraw, there are some because of the "feng shui treasure" and swallow.

\section{Everywhere "Crisis" Results}

The expansion of the situation has aroused the concern of the local media and business sectors. In the multi-intervention and the pressure of public opinion, suppliers and department stores finally shake hands. But the supplier is worried about the future, the department store to make a compromise is only temporarily get a chance to quell. If retailers do not recognize the relationship 
with the supplier's fish and water, dishonest and trustworthy, do not comply with the "open, fair and just" rules of the game, then the future shopping malls and suppliers is difficult to live in peace. Then this is only the beginning of the "war".

\section{The Theoretical Roots of Conflict}

Channel conflict to channel cooperation as a prerequisite. No channel members of the cooperation, there is no conflict between members of the channel. Channel members to cooperate between the conflict is also inevitable.

Many factors can lead to channel conflict, there are seven are the most basic: the role of unclear, resource scarcity, perceived differences, expectations of error, decision-making areas are different, inconsistent goals, communication barriers. Nanchang Department Store events can be analyzed from target inconsistencies and communication barriers.

\section{Conflict-Induced Changes in Channel Cooperation}

Due to the inconsistency between the supplier and the retailer's goal, so that suppliers and retailers have different channels of cooperation, in this case due to retailers arbitrary charges, access threshold is high, so that suppliers and retailers Between the channel cooperation "swallow" to continue cooperation and "parted ways" to terminate cooperation. Figure 1 is a conceptual model.

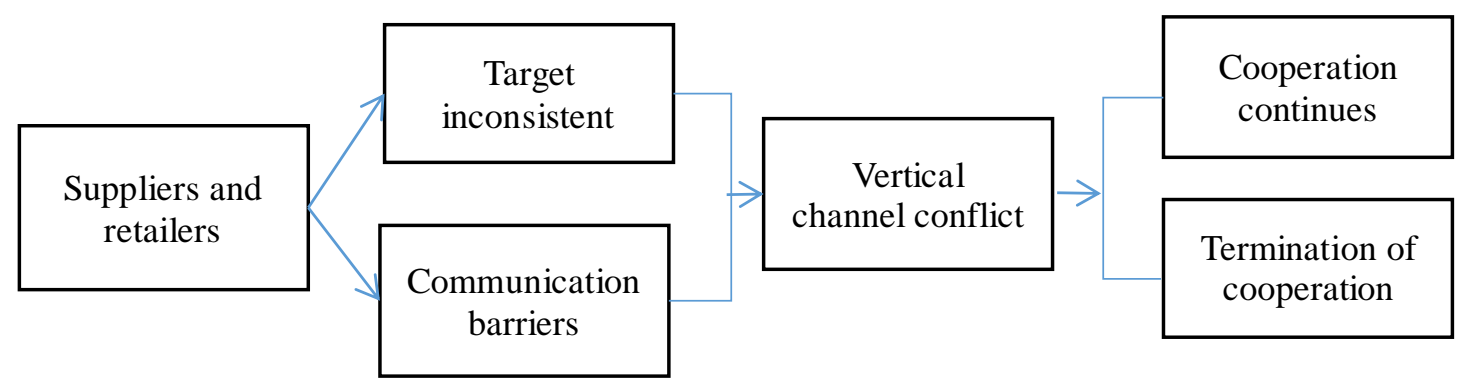

Figure 1. Conceptual model diagram

\section{"Parting" Their Own Good}

According to the goal of inconsistency theory, suppliers and retailers have a common goal (such as meeting the needs of a common end customer, improving channel efficiency and integrating channel competitiveness), and each has its own specific goals. When the supplier and the retailer have their own goals, When the retailer's goal is inconsistent or incompatible, it is prone to conflict.

\section{"Swallow" To Continue Cooperation}

In this paper, due to the vertical channel conflict between suppliers and retailers, some people chose to terminate cooperation, channel cooperation rupture. There is a part of the artificial is to choose "swallow" to continue to cooperate in the retailer under the high pressure to survive, this cooperation is only temporary, is the beginning of a larger conflict, the supplier will eventually because of the domineering of retailers and power channels Be in crisis. Retailers are aware of the interdependence of suppliers or suppliers in the choice of retailers is fair to both sides, suppliers and retailers can be between the channel conflict can be adjusted from the root causes of cooperation between the two sides can be durable.

\section{Resolve Vertical Channel Conflict Methods}

Vertical channel conflict is a market crisis for suppliers. Suppliers must first establish a "preventive measures" awareness and take the relevant preventive action. At the same time, suppliers and retailers in cooperation, to continue to enhance their channel control capabilities to prevent the emergence of vertical channel conflict. If a vertical conflict occurs, Then the supplier should be through the relevant measures to effectively solve[5].

Precautions beforehand. First of all, in the early research on the basis of the choice of good retailers, lay the foundation for the latter part of the cooperation. Suppliers can not only consider the 
strength of retailers, but also consider their own cooperation with each other equality;Consider the retail business capacity, network size, reputation, financial status, internal management level, historical experience, willingness to cooperate[6]. Suppliers through the careful selection of retailers, to establish a stable and mutually beneficial value chain system. In particular, suppliers should pay attention to the effective choice of retailers, even if the relatively high cost of investment, can effectively reduce the "follow-up conflict" the possibility of the overall cost of the supplier to reduce the cost and effective guarantee manufacturing cityStable development of the field.

Things in control. In the process of cooperation between suppliers and retailers, suppliers also continue to strengthen the control of retailers. Only in this way can the retailer have a long-term sense of cooperation with the supplier.Use brand control distributors. From the channel management point of view, the product brand through the impact of the consumer to complete the impact on the entire channel. As suppliers have to establish their own brand, but the retailer's brand can only play a role in the channel, the role of small consumers. Retailer's brand is often attached to the agent of the product brand, without the support of suppliers, retailer's brand price will be greatly reduced[7]. For retailers, a good brand of products means profit, sales, image, but also means that the increase in sales efficiency. In general, the best-selling products need to distributors of marketing efforts is relatively small, so the retailer's sales cost is relatively low, but also drive the sale of other products. This can be recovered from other products above the profits. At the same time because the sales speed is relatively fast, improve the turnover rate of retailers funds. Therefore, suppliers as long as the consumer level to establish their own good brand image, you can exert influence on the channel. Distributors through the supplier's "brand name" effect to improve their brand value, at the same time, through the operation of the brand to effectively reduce their own sales costs, bring sales efficiency.

In the process of cooperation between suppliers and retailers, establish and improve the communication mechanism so that the two sides can meet each other's needs as much as possible, to each other to understand, understand and achieve a win-win situation[8].

Incident processing. The emergence of channel conflict is always possible at any time, for the emergence of channel conflict, manufacturers can be resolved through the following channels. A timely communication. B Negotiate negotiations or litigation. C looking for other retailers instead.

\section{References}

[1] Philip Kotler,Sidney J Levy.Broadening the Concept of Marketing. Journal of Marketi-ng.1969.

[2] Julian Dent.Distribution Channels: Understanding and Managing Channels to Market. Kogan Page . 2011

[3] Keysuk Kim,Changho Oh."On distributor commit-ment in marketing channels for indust-rial products:contrastbetween the United States and Japan". Journalof International Mark--eting . 2002

[4] Anne Coughlan,Erin Anderson,Louis W. Stern,Adel E1-Ansary.Marketing Channels. 2006.

[5] Fedja Netjasov,Obrad Babi. Framework for airspace planning and design based on conflict risk assessment[J]. Transportation Research Part C. 2013.

[6] Fedja Netjasov. Framework for airspace planning and design based on conflict risk assessment[J]. Transportation Research Part C. 2012.

[7] Fedja Netjasov,Milan Janic. A review of research on risk and safety modelling in civil aviation[J]. Journal of Air Transport Management. 2008 (4)

[8] Brown James R, Day Ralph L. Mearsures of Manifest Conflict in Distribution Channels[J].Joumal of MarketingReserch,1981,(8):263-274. 